\title{
Mapeamento Geomorfológico da Bacia Hidrográfica do Arroio Pelotas, RS
}

\author{
Geomorphological Mapping of the Hidrographic Basin Arroio Pelotas, $R S$
}

Mapeo Geomorfológico de la Cuenca Hidrográfica del Arroyo Pelotas, RS

Érica Insaurriaga Megiato ${ }^{1}$

Nina Simone Vilaverde Moura²

\begin{abstract}
RESUMO: O objetivo deste trabalho foi mapear a geomorfologia da Bacia Hidrográfica do Arroio Pelotas (BHAP) a partir da metodologia da compartimentação do relevo até o $3^{\circ}$ táxon, onde foram mapeadas as Unidades dos Padrões de Formas Semelhantes do Relevo. O mapa de geomorfologia da BHAP apresentou oito classes distintas, das quais cinco foram mapeadas na morfoestrutura do Escudo Sul-riograndense, ocupando as respectivas porcentagens da área total da bacia: Morros com Topos Planos (11\%), Morros com Topos Convexos e Vertentes Suaves (35\%), Morros com Topos Convexos e Vertentes Íngremes (13\%), Colinas com Topos Convexos (15\%) e Planície Flúvio-coluvial (3\%). Na unidade morfoestrutural da Bacia Sedimentar de Pelotas foram mapeadas três classes, ocupando as respectivas porcentagens da área de estudo: Planície Lagunar e Planície Lagunar com Dunas e Banhados (15\%) e Planície Flúvio Lagunar (8\%).
\end{abstract}

PALAVRAS-CHAVE: Relevo. Morfoestrutura. Morfoescultura.

ABSTRACT: The purpose of this work was to map the geomorphology of the Arroio Pelotas Basin $(A P B)$ from the methodology of the subdivision of the relief to the 3rd taxon, where the Patterns Units of the Similar Forms of Relief were mapped. The APB geomorphology map presented eight distinct classes. Of these, five were mapped in the morphostructure of the South Rio Grande do Sul Shield, occupying the respective percentages of the total area of the basin: Flap Top Hill (11\%), Hill with Convex Top and Mild Strands (35\%), Steep slopes (13\%), Hills with Convex Tops (15\%) and Fluvialcolluvial Plain (3\%). In the morphostructural unit of the Pelotas Sedimentary Basin three classes were mapped, occupying the respective percentages of the study area: Pond Plain and Pond Plain with Dunes and Marsh Terrain (15\%) and Plain Fluvial Pond (8\%).

KEY WORDS: Relief. Morphostructure. Morphosculpture.

RESUMEN: El objetivo del presente trabajo fue mapear la geomorfología de la Cuenca Hidrográfica del Arroyo Pelotas (CHAP) a partir de la metodología de la compartimentación del relieve hasta el $3^{\circ}$ taxón, donde fueron mapeadas las unidades de las formas semejantes del relieve. El mapa de geomorfología de CHAP presentó ocho clases distintas. De las cuales cinco fueron mapeadas en la morfoestructura del Escudo Sur-riograndense, ocupando los respectivos porcentajes del área total de la cuenca: Morros con Topos Planos (11\%), Morros con Topos Convexos y Vertentes Suaves (35\%), Morros con Topos Convexos y Vertientes Íngremes (13\%), Colinas con Topos Convexos (15\%) y Llanura Flúvio-coluvial (3\%). En la unidad morfo estructural de la Cuenca Sedimentaria de Pelotas fueron asignadas tres clases, ocupando los respectivos porcentajes del área de estudio: Llanura Lagunar y Llanura Lagunar con Dunas y Bañados (15\%) y Llanura Flúvio Lagunar (8\%).

PALABRAS-CLAVE: Relieve. Morfoestructura. Morfoescultura.

\footnotetext{
1 Universidade Federal do Rio Grande do Sul, Av. Bento Gonçalves, 9500 - Prédio 43113/203 Porto Alegre/RS - CEP: 91540000 - ericaimeg@gmail.com.

2 Universidade Federal do Rio Grande do Sul, Av. Bento Gonçalves, 9500 - Prédio 43113/203 Porto Alegre/RS - CEP: 91540000 - ninavilaverdemoura@gmail.com.
} 


\section{INTRODUÇÃO}

Os estudos de caráter geomorfológico são aqueles que permitem o conhecimento das diversas formas de relevo que a superfície terrestre apresenta. De acordo com Christofoletti (1980) estas formas de relevo foram esculpidas por algum processo do meio físico ou por grupos de processos diferentes que interagiram resultando na diversidade do relevo terrestre.

O relevo terrestre é formado a partir da integração dos processos derivados de ações de forças endógenas, aquelas resultantes da tectônica de placas e pelas forças exógenas, que são capazes de esculpir as suas formas através do intemperismo e da erosão. Pela ação das forças internas da terra resulta a morfoestrutura do relevo.

A partir das forças exógenas ou da atuação constante das forças externas sobre o relevo nas diversas morfoestruturas caracteriza-se a formação das unidades morfoesculturais. Suertegaray e Fujimoto (2004) afirmam que as morfoesculturas são as feições do relevo da superfície terrestre, que são impressas pela ação dos climas do passado e atuais sobre a morfoestrutura ao longo do tempo geológico.

Nos estudos ambientais de cunho geográfico, a geomorfologia possui um caráter integrador, pois permite o entendimento da evolução espaço-temporal dos processos, os quais podem ser analisados antes e depois da intervenção humana nas áreas estudadas (ROSS, 2000).

Para a avaliação das dinâmicas naturais e da intervenção humana, os estudos geomorfológicos são indispensáveis, pois através do mapeamento e análise geomorfológica é possível espacializar informações importantes para o conhecimento dos ambientes e sobre o grau de intervenção antrópico no modelado terrestre.

Os mapeamentos geomorfológicos podem ser utilizados em diversos projetos de planejamento e gerenciamento ambiental a partir de uma visão integradora (GUERRA; MARÇAL, 2006; MEGIATO, 2011). Estes mapas permitem o conhecimento das formas de relevo e suas particularidades, possibilitando a tomada de decisões dos órgãos competentes como sobre o potencial de utilização dos solos em áreas urbanas e rurais.

De acordo com a classificação utilizada por Ross (1992) que se baseia em método já utilizado no Projeto RADAM (IBGE, 1986), a compartimentação do relevo pode ser classificada em até seis táxons ou categorias de relevo. Nesta classificação, o $1^{\circ}$ táxon é relacionado às grandes unidades de relevo, representando a morfoestrutura, ou seja, as características estruturais genéticas que constituem o relevo. $O 2^{\circ}$ táxon representa as unidades morfoesculturais que são unidades menores, geradas pelas ações climáticas subsequentes no tempo geológico sobre a morfoestrutura. 
A compartimentação relacionada ao 3 o táxon possui dimensão inferior ao segundo táxon, representando as Unidades dos Padrões de Formas Semelhantes do Relevo ou os Padrões de Tipos de Relevo. Nestas unidades os processos climáticos atuais são facilmente notados, constituindo conjuntos de formas menores de relevo, que apresentam diferenças em função da rugosidade ou dos índices de dissecação, bem como no formato de topos, vertentes e vales.

O objetivo deste trabalho foi mapear a geomorfologia da Bacia Hidrográfica do Arroio Pelotas (BHAP) na escala 1:50.000 a partir da metodologia da compartimentação do relevo, dividindo a unidade de estudo até $03^{\circ}$ táxon, onde foram mapeadas as Unidades dos Padrões de Formas Semelhantes do Relevo.

\section{MATERIAIS E MÉTODOS}

\section{Localização e caracterização da área de estudo}

A Bacia Hidrográfica do Arroio Pelotas (BHAP) situa-se (figura 1) no estado do Rio Grande do Sul na Região Hidrográfica do Litoral e faz parte da bacia dos rios Piratini/São Gonçalo. A área de estudo localiza-se entre as coordenadas geográficas $52^{\circ} 10^{\prime}$ e $52^{\circ} 50^{\prime} \mathrm{W}$ e $31^{\circ} 20^{\prime}$ e $31^{\circ} 50^{\prime} \mathrm{S}$ e possui uma área de aproximadamente 910 quilômetros quadrados. Com relação aos municípios, a BHAP abrange Pelotas, Canguçu, Morro Redondo e Arroio do Padre, todos localizados na Zona Sul do Rio Grande do Sul.

Encontra-se dentro dos limites do município de Pelotas a maior porção da bacia hidrográfica em questão. O Arroio Pelotas, seu principal curso, deságua no canal São Gonçalo. Com relação ao meio físico, a BHAP situa-se sobre duas províncias geomorfológicas importantes, em sua porção norte sobre o Planalto Sul-rio-grandense e na porção sul, sobre a Planície Costeira. 
Figura 1- Localização da BHAP nos municípios da zona Sul do RS

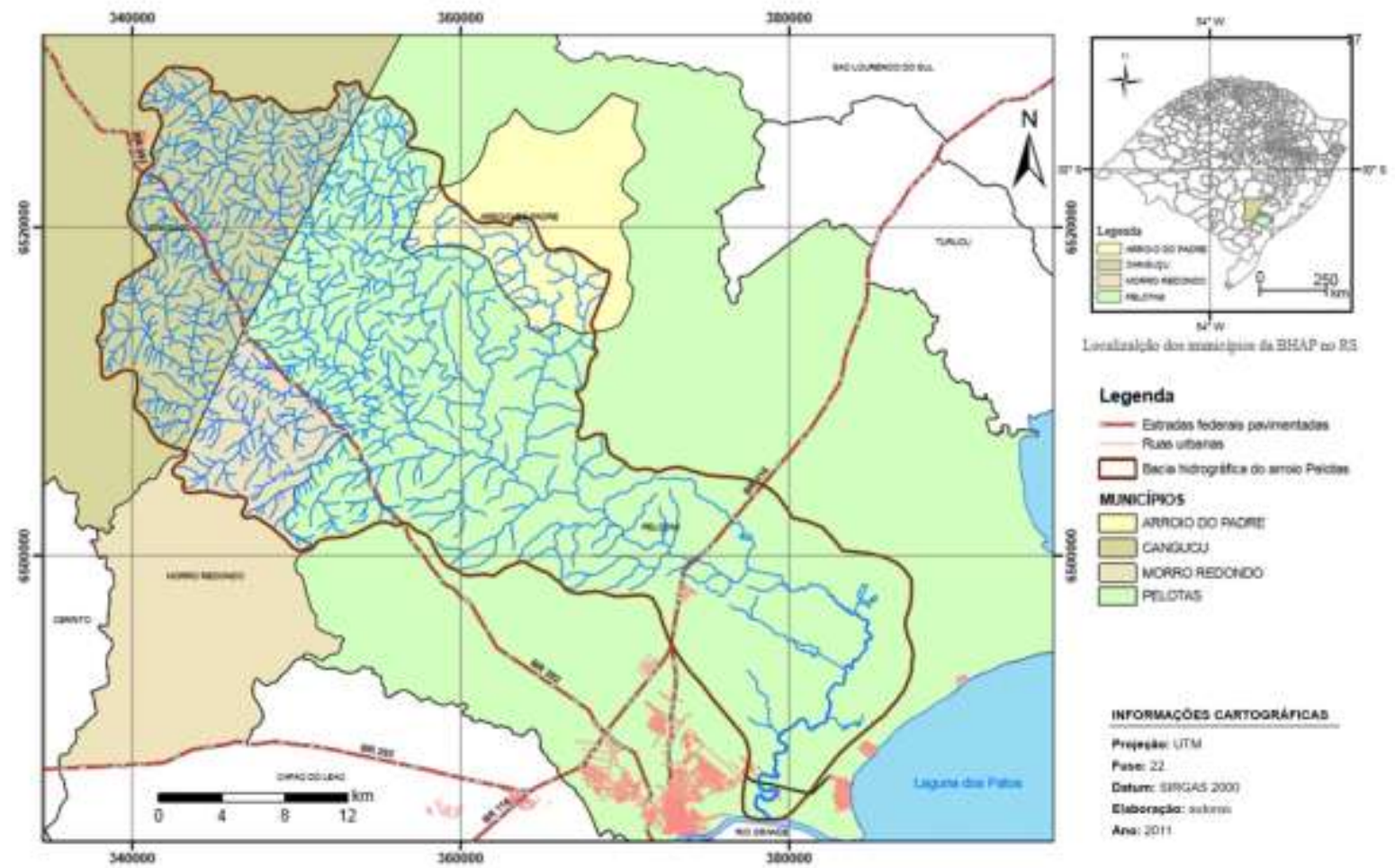

Fonte: Megiato (2011).

\section{Materiais}

Para a elaboração do mapa geomorfológico da BHAP foi utilizada a base cartográfica contínua do Rio Grande do Sul em escala 1:50.000 (HASENACK; WEBER, 2010). Para a área da Planície Costeira foram utilizados os mapas da CPRM (Companhia de Pesquisa de Recursos Minerais) e do RADAM - Folha SH 22 (IBGE, 1986). Para a atualização de informações na área foi utilizado também o mapeamento geológico geomorfológico de Pelotas, elaborado pelo NET (Núcleo de Estudos da Terra) da UFPEL (MARTH; KOESTER; ARNDT, 2008). Ainda para auxílio do reconhecimento e interpretação das feições do relevo foi utilizada uma imagem de satélite Landsat 5 (órbita ponto 221_82), sensor TM (Thematic Maper) com resolução espacial de 30 metros.

Os mapas temáticos que proporcionaram a elaboração do produto cartográfico final de geomorfologia foram confeccionados a partir da utilização dos softwares ArcGis 9.3, ENVI 4.2 e Cartalinx. Para a análise das classes obtidas no mapeamento geomorfológico foram feitas saídas de campo para reconhecimento das feições in locu e para aquisição de fotografias a fim de ilustrar as referidas classes. 


\section{Métodos}

Para a elaboração do mapa geomorfológico da BHAP foi necessária primeiramente a confecção de alguns mapas temáticos que serviram de subsídio para o mapa final. Para tanto foi utilizada a base cartográfica digital em escala 1:50.000 (HASENACK; WEBER, 2010), usando-se as informações vetoriais contidas na base. As curvas de níveis e os pontos cotados extraídos das cartas topográficas foram manipulados no programa Arcgis 9.3 para a elaboração de um Modelo Numérico de Elevação do Terreno (MNT) para a área de estudo. A partir do MNT foi possível a delimitação da bacia hidrográfica, mapeando seus limites a partir dos divisores de águas.

O MNT também serviu de subsídio para a confecção do mapa geomorfológico, auxiliando na interpretação dos padrões de relevo existentes na BHAP. Junto com o MNT foi utilizado um modelo de sombreamento do relevo (VALERIANO, 2008), que permitiu observar os detalhes dos padrões de formas de relevo existentes na área de estudo. A partir deste produto também foi elaborado o mapa de declividades (clinográfico) da área de estudo, fatiando-o em classes de acordo com a proposta de Ross (1994).

O MNT (Modelo Numérico do Terreno) ou modelo digital de elevação (MDE) pode ser definido como uma representação matemática da distribuição espacial de características vinculadas a uma superfície real. O MDE possibilitou o cálculo de áreas, declividades, geração de imagens com sombreamento em níveis de cinza, classificações através dos intervalos desejados e mostrar perspectivas tridimensionais do relevo. Essa metodologia se baseia na formação de triângulos a partir dos valores de altitude do terreno; sendo que para cada um dos três vértices da face do triângulo são armazenadas as coordenadas de localização $(x, y)$ e o atributo $z$. O TIN é uma estrutura vetorial que inclui tipos de vetor nó e arco, ou seja, ponto e linha.

Para o MDE foram utilizados os valores das linhas das curvas de níveis, vetorizadas com valores de 20 em 20 metros e os valores dos pontos cotados das cartas topográficas contidos na base cartográfica, os quais foram armazenados com vetores do tipo ponto. Este arquivo vetorial foi inserido no programa ArcGis 9.3, onde foi gerado o MDE. Este produto foi classificado, separando com as cores hipsométricas os valores de terreno, formando um degradê de cores correspondentes a menor elevação até o ponto mais alto do terreno, os quais foram divididos de 20 em 20 metros. Com base no MDE, aplicou-se um modelo de sombreamento em níveis de cinza, mostrando-o com uma transparência de 50\% sobreposto ao sombreamento. Esta sobreposição permitiu a visualização do terreno em três dimensões, facilitando a identificação dos divisores de água da bacia hidrográfica em questão e de sua rede de drenagem. 
O mapa de declividades da Bacia Hidrográfica do Arroio Pelotas foi elaborado a partir do modelo de elevação do terreno inserido no programa ArcGis 9.3, a partir da função slope no referido software, obteve-se o mapa clinográfico. O modelo de declividades foi classificado de acordo com a proposta de Ross (1994), que define as classes de fragilidade com relação aos graus de declividade do terreno.

As classes dos diferentes padrões de relevo foram obtidas através de um cruzamento num Sistema de Informações Geográficas (SIG). As seguintes variáveis foram utilizadas no cruzamento: as classes de declividades e amplitude topográfica, de acordo com a taxonomia do relevo utilizada por Ross (1992), metodologia já utilizada pelos mapeamentos realizados no Brasil na década de 1970 pelo projeto RADAM (Radar da Amazônia) (IBGE, 1986) contando também com a abordagem do IPT (Instituto de Pesquisas Técnicas), citada por Florenzano (2008), a qual apresenta uma metodologia utilizada para os padrões de relevo em áreas de degradação, conforme apresentado a seguir (quadro 1), sendo adaptada a nomenclatura, conforme particularidades da área.

Quadro 1 - Principais critérios utilizados na identificação de sistemas de relevo de degradação

\begin{tabular}{|l|l|l|}
\hline $\begin{array}{l}\text { Conjuntos de sistemas de } \\
\text { sistemas de relevo }\end{array}$ & $\begin{array}{l}\text { Declividade dominante das } \\
\text { vertentes }\end{array}$ & Amplitudes locais \\
\hline Relevo Colinoso & 0 a $15 \%$ & $<100 \mathrm{~m}$ \\
\hline $\begin{array}{l}\text { Relevo de Morros com } \\
\text { Vertentes Suavizadas }\end{array}$ & 0 a $15 \%$ & $100 \mathrm{a} 300 \mathrm{~m}$ \\
\hline Relevo de Morrotes & $>15 \%$ & $<100 \mathrm{~m}$ \\
\hline Relevo de Morros & $>15 \%$ & $100 \mathrm{~m}$ a $300 \mathrm{~m}$ \\
\hline Relevo Montanhoso & $>15 \%$ & $>300 \mathrm{~m}$ \\
\hline
\end{tabular}

Fonte: Florenzano (2008).

$\mathrm{Na}$ área da Planície Costeira, que é uma área de deposição, a metodologia precisou ser adaptada, utilizando-se como base o mapa geológico da CPRM e o mapa geomorfológico do RADAM Brasil. Para a definição das classes de relevo nesta área, utilizou-se também o mapeamento geológico geomorfológico de Pelotas, elaborado pelo NET (Núcleo de Estudos da Terra) da UFPEL (MARTH; KOESTER; ARNDT, 2008), para auxílio na atualização de informações na porção sul da Bacia Hidrográfica do Arroio Pelotas.

A partir da identificação dos padrões morfoesculturais da BHAP, pode-se chegar ao terceiro táxon a partir das declividades predominantes em cada padrão encontrado. Para conclusão do mapa geomorfológico, foram realizadas interpretações em imagem de satélite do tipo Landsat 5 TM, com o intuito de atualizar informações sobre o relevo, a imagem sobreposta ao MDE permitiu um melhor reconhecimento das feições geomorfológicas. Para confirmação das informações obtidas a partir dos mapeamentos, foram realizadas saídas de 
campo, tanto para confirmação dos resultados quanto para obtenção de fotografia das classes de geomorfologia.

\section{RESULTADOS E DISCUSSÕES}

\section{Modelo de Elevação do Terreno (MDE) da BHAP}

O MDE (Modelo de Elevação do Terreno) da Bacia Hidrográfica do Arroio Pelotas possibilitou o cálculo das áreas respectivas para cada classe de altimetria, de acordo com o intervalo pré-estabelecido de 20 em 20 metros. O gráfico abaixo (figura 2) permite observar a distribuição das altitudes do relevo na Bacia Hidrográfica do Arroio Pelotas.

Figura 2 - Gráfico mostrando a distribuição de altitudes na BHAP

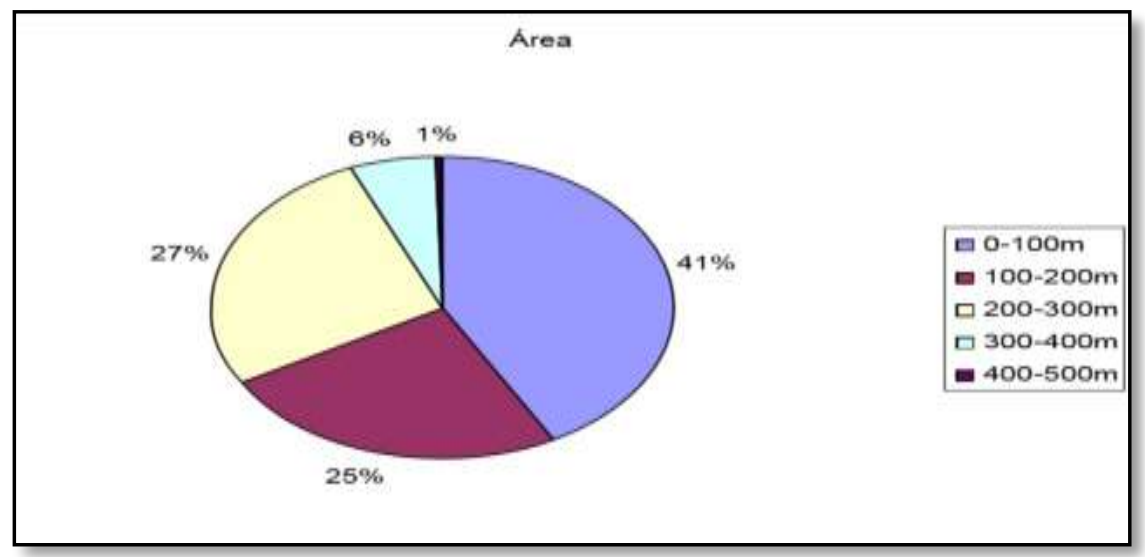

Fonte: Megiato (2011).

A altimetria foi classificada de 100 em 100 metros, correspondendo a cinco classes, mostrando que $45 \%$ da área total da BHAP possui altimetria que varia do nível do mar até os 100 metros, e que apenas $2 \%$ da área total possui valores altimétricos que variam dos 301 aos 500 metros de altitude. O MDE (figura 3) além de permitir a representação do relevo da BHAP a partir das cores hipsométricas possibilitou também a elaboração do mapa clinográfico e do mapa geomorfológico.

O mapa de declividades da Bacia Hidrográfica do Arroio Pelotas foi elaborado a partir do modelo de elevação do terreno. O modelo foi classificado em seis classes de declividades, seguindo uma metodologia proposta por Flores et al. (2007), definindo os tipos de relevo de acordo com as porcentagens de declividades (quadro 2). 
Figura 3 - Modelo de Elevação do Terreno da BHAP

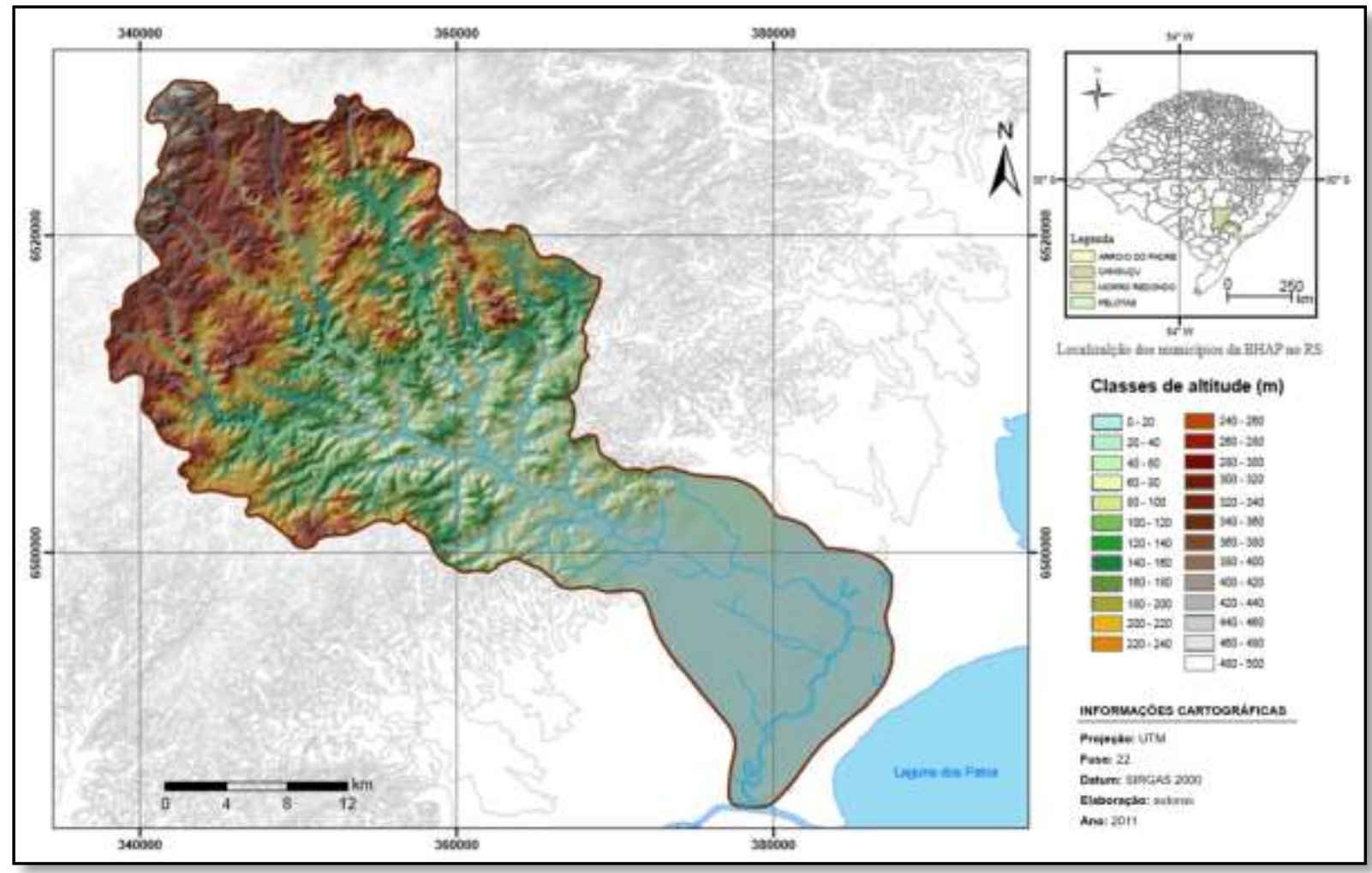

Fonte: Megiato (2011).

Quadro 2 - Classes de declividade e tipos de relevo

\begin{tabular}{|l|l|l|}
\hline Declividades \% & Classes & Área (ha) \\
\hline $0-3$ & Plano & 43255,8 \\
\hline $3-8$ & Suave ondulado & 8713,5 \\
\hline $8-13$ & Ondulado & 14404,5 \\
\hline $13-25$ & Moderadamente ondulado & 13829,5 \\
\hline $25-45$ & Forte ondulado & 10288,9 \\
\hline$>45$ & Montanhoso & 583,6 \\
\hline
\end{tabular}

Fonte: Megiato (2011).

\section{Mapa de declividades da BHAP}

As declividades consistem nas medidas de inclinação da superfície do solo em relação à horizontal. Quanto maior for o grau de inclinação do terreno, é indicado pela maior porcentagem. Os modelos de declividades ou mapas clinográficos permitem a avaliação dos riscos de erosão dos solos, do potencial de uso destes solos para a agricultura e mecanização e podem contribuir para outros tipos de mapeamento, como o de fragilidade ambiental por exemplo.

O mapa clinográfico da bacia do Arroio Pelotas (figura 4) foi classificado de acordo com as classes de fragilidade propostas por Ross (1994). Tal classificação consiste em 
cinco classes que apresentam diferentes graus de fragilidade, sendo elas, cinco classes com graus de fragilidade de Muito Fraca ( $<6 \%$ ) a Muito Forte (acima dos $30 \%)$. A partir do cálculo destas áreas foi possível analisar que 52\% da BHAP apresenta fragilidade Muito Fraca com relação às declividades e apenas $4 \%$ da área total da bacia hidrográfica em questão pode ser classificada com fragilidade Muito Forte com relação às declividades.

Figura 4 - Mapa clinográfico da BHAP

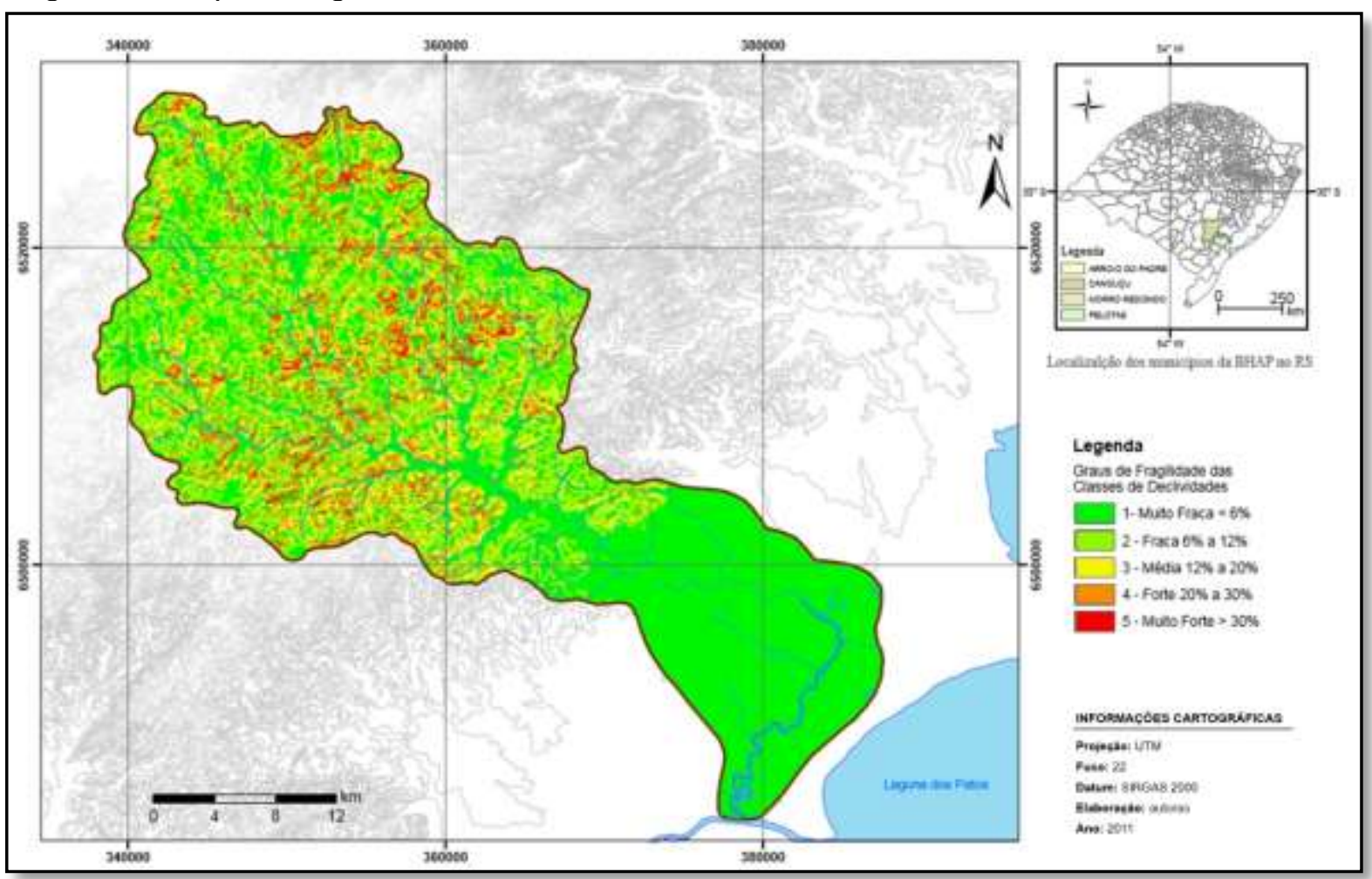

Fonte: Megiato (2011)

\section{Mapeamento geomorfológico da Bacia Hidrográfica do Arroio Pelotas}

Com relação aos padrões e tipos de formas de relevo, o mapa geomorfológico foi classificado a partir de oito classes diferentes, onde cinco delas inserem-se no contexto da unidade morfoestrutural Escudo Sul-rio-grandense e respectivamente fazem parte da morfoescultura do Planalto Uruguaio Sul-rio-grandense. Já na unidade morfoestrutural da Bacia Sedimentar de Pelotas foram mapeados três diferentes tipos de padrões de forma de relevo, os quais têm como morfoescultura a Planície e Terras Baixas Costeiras. O quadro a seguir (quadro 3) apresenta os padrões de forma de relevo encontrados na área de estudo relacionados às suas respectivas morfoestruturas e morfoesculturas.

O mapa geomorfológico da BHAP (figura 5) permitiu a espacialização das classes dos tipos de padrões de forma de relevo e a quantificação das áreas referentes a cada classe. A maior porção da Bacia Hidrográfica do Arroio Pelotas foi classificada de acordo com os 
padrões e formas de relevos pertencendo à classe dos Morros com Topos Convexos e Vertentes Suaves, totalizando $35 \%$ da área total da bacia. Esse tipo de feição geomorfológica se caracteriza na área de estudo por apresentar vertentes suaves com topos convexos, formas estas que foram arredondadas e suavizadas pelo desgaste erosivo e ação dos agentes do intemperismo. Tal padrão geomorfológico é encontrado na área de estudo em altitudes acima dos 120 metros com declividades que variam de Fraca a Forte.

Quadro 3 - Taxonomia e padrões de forma de relevo da BHAP

\begin{tabular}{|c|c|c|}
\hline 1ํo Táxon & 2ำTáxon & 3o Táxon \\
\hline Morfoestrutura & Morfoescultura & Padrões de Formas de Relevo \\
\hline \multirow{4}{*}{ Escudo Sul-riograndense } & \multirow{4}{*}{$\begin{array}{l}\text { Planalto Uruguaio Sul- } \\
\text { riograndense }\end{array}$} & Morros com topos planos \\
\hline & & $\begin{array}{l}\text { Morros com topos convexos e } \\
\text { vertentes suaves }\end{array}$ \\
\hline & & $\begin{array}{l}\text { Morros com topos convexos e } \\
\text { vertentes íngremes }\end{array}$ \\
\hline & & Colinas com topos convexos \\
\hline \multirow{4}{*}{$\begin{array}{l}\text { Bacia Sedimentar de } \\
\text { Pelotas }\end{array}$} & \multirow{4}{*}{$\begin{array}{l}\text { Planície e Terras Baixas } \\
\text { Costeiras }\end{array}$} & Planície lagunar \\
\hline & & $\begin{array}{l}\text { Planície lagunar com dunas e } \\
\text { banhados }\end{array}$ \\
\hline & & Planície flúvio lagunar \\
\hline & & Planície flúvio-coluvial \\
\hline
\end{tabular}

Fonte: Megiato (2011).

Figura 5 - Mapa geomorfológico da Bacia Hidrográfica do Arroio Pelotas

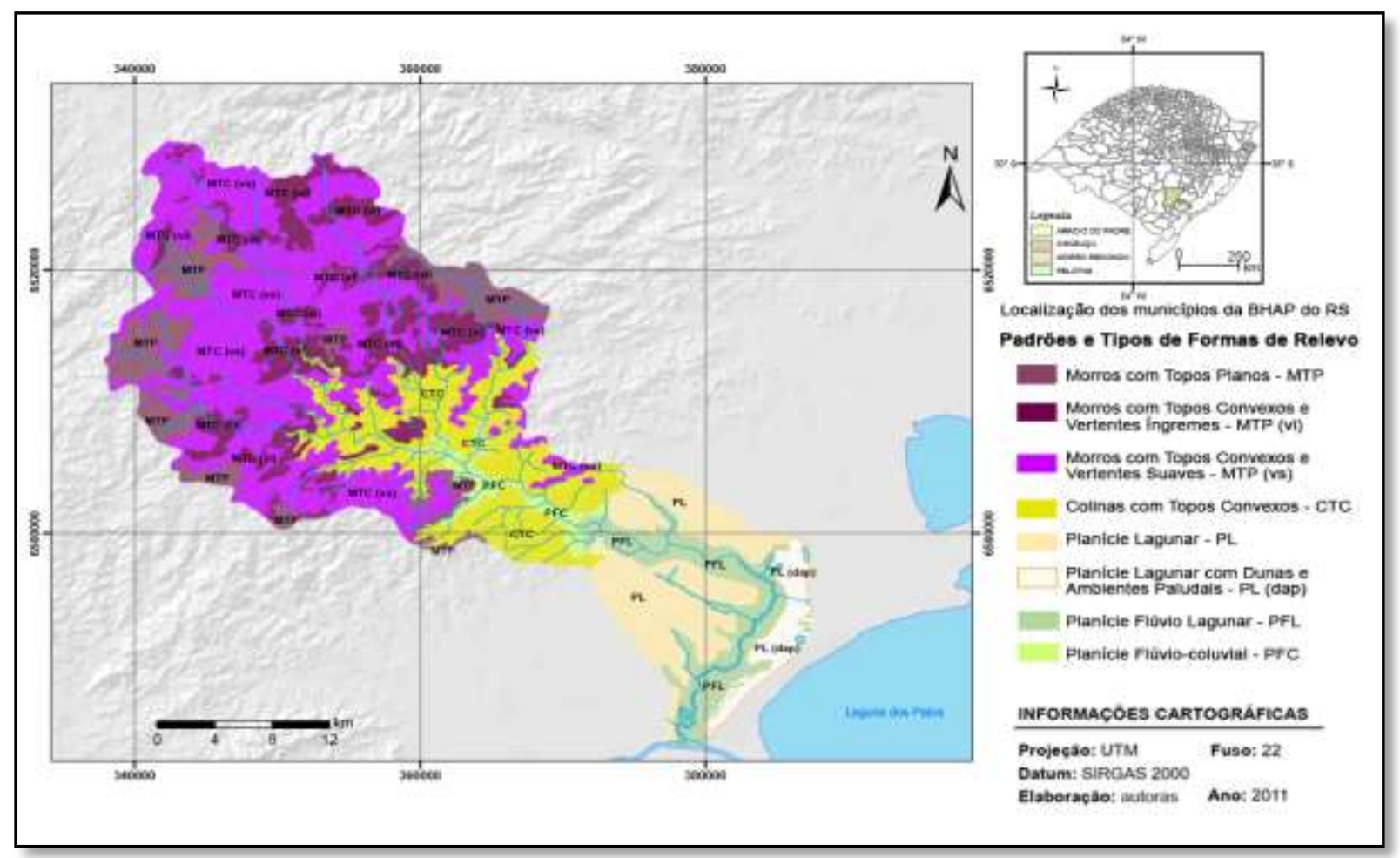

Fonte: Megiato (2011). 
A classe dos Morros com Topos Convexos e Vertentes Íngremes ocupa respectivamente $13 \%$ da área total da Bacia Hidrográfica do Arroio Pelotas. Tais feições geomorfológicas são encontradas na BHAP a partir dos 140 metros de altitude com declividades predominantes acima dos $20 \%$, as quais são consideradas de Forte a Muito Forte.

Os Morros com Topos Planos na BHAP, de $11 \%$ na área de estudo, localizam-se principalmente nos divisores de água da bacia. Tal padrão de forma de relevo encontra-se na BHAP em altitudes acima dos 180 metros, com declividades predominantes de Média a Forte.

O padrão de forma de relevo em colinas é encontrado na área de estudo em 15\% do total da área da BHAP. Esse tipo de relevo se caracteriza pelas feições suavemente onduladas a onduladas, com vertentes suaves. As colinas são encontradas na BHAP acima dos 20 metros de altitude e possuem declividades predominantes de Muito Fraca à Média.

$\mathrm{Na}$ morfoestrutura do Escudo Sul-rio-grandense encontra-se também a classe denominada Planície Fluvio-coluvial, ocupando 3\% da área da BHAP. Esse padrão de forma de relevo é encontrado nas planícies dos cursos d'água da bacia, onde se depositam sedimentos oriundos das áreas mais elevadas adjacentes (colúvio) e sedimentos retrabalhados pela ação fluvial. No presente trabalho, essa classe se refere à planície de inundação do Arroio Pelotas, devido à escala de realização do trabalho (1:50.000). Nessas áreas as altitudes são inferiores a 20 metros, com declividades classificadas como Muito Fracas.

Na morfoestrutura da Bacia Sedimentar de Pelotas o mapa geomorfológico foi dividido em três padrões de formas de relevo distintas: Planície Lagunar, Planície Lagunar com Dunas e Banhados e Planície Flúvio-lagunar. As duas classes relacionadas às Planícies Lagunares juntas representam 15\% da área total da BHAP. Essas feições geomorfológicas se caracterizam por serem áreas deposicionais dos sistemas laguna-barreira do Período Quaternário, originados a partir das transgressões e regressões marítimas e também pelos depósitos eólicos. Com relação às altitudes, essas áreas ficam abaixo dos 20 metros, sendo que algumas áreas têm o mesmo nível do mar. São áreas de relevo plano, com declividades Muito Fracas.

A classe referente à Planície Flúvio-lagunar na BHAP ocupa uma porção de $8 \%$, caracterizando depósitos de origem fluvial que se depositaram através dos sistemas lagunabarreira e que se depositam pela ação dos corpos d'água que integram a BHAP. Nessas áreas as altitudes são abaixo dos 20 metros, chegando ao nível do mar em algumas áreas, as declividades são de Fraca a Muito fraca. Na imagem a seguir (figura 6) as fotografias ilustram tipos de padrões de formas de relevo encontrados na BHAP. 
Figura 6 - Padrões de formas de relevo na BHAP. A foto 1 representa os Morros com Topos Planos, a foto 2 mostra a Planície Flúvio-coluvial do Arroio Pelotas
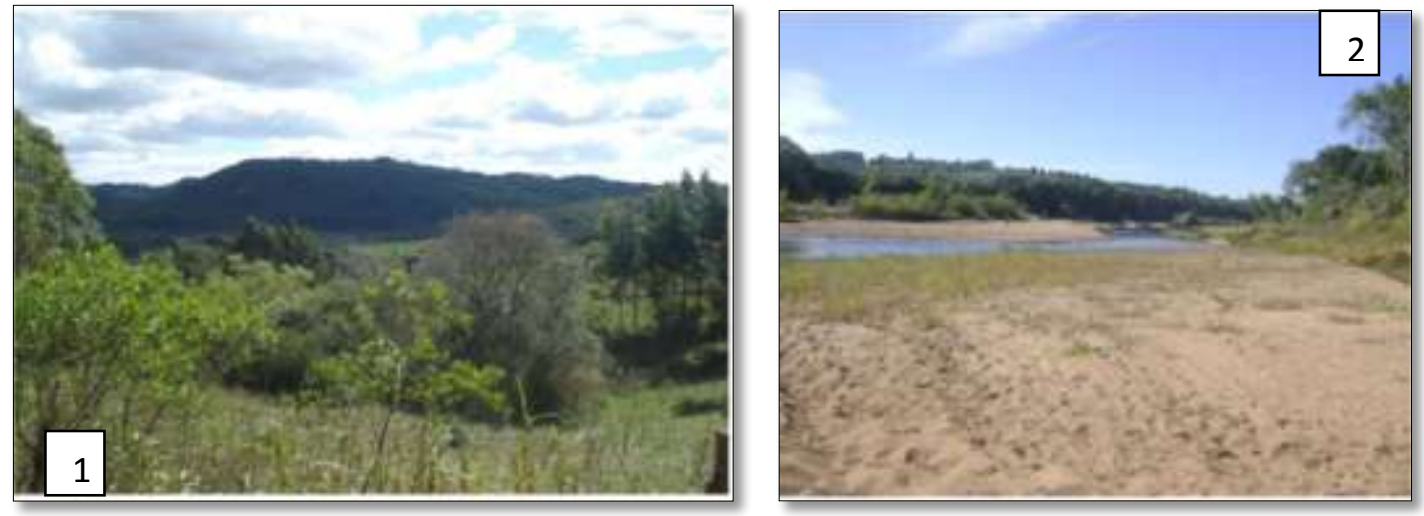

Fonte: Megiato (2011).

\section{CONSIDERAÇÕES FINAIS}

O mapa geomorfológico da Bacia Hidrográfica foi elaborado a partir de outros mapas temáticos, como MNT e mapa de declividades, que possibilitaram o cruzamento de informações e elaboração do produto cartográfico final. Os aspectos do meio físico são importantes para a análise e conhecimento das características naturais dos ambientes.

As características geológicas da área de estudo foram importantes para definição dos passos metodológicos para a confecção do mapa geomorfológico nas distintas unidades morfoestruturais. Além de possibilitar o conhecimento de geomorfologia a partir dos padrões e formas de relevo, o mapa geomorfológico serve de subsídio ao planejamento ambiental e ordenamento territorial na área de estudo.

A partir do mapeamento da BHAP foi possível a identificação das principais classes de padrões de forma de relevo em cada unidade morfoescultural da área de estudo. No Planalto Uruguaio Sul-riograndense a classe predominante foi a dos Morros com Topos Convexos e Vertentes Suaves, totalizando $35 \%$ da área total da bacia. Na Planície e Terras Baixas Costeiras, a classe que prevaleceu foi a das Planícies Lagunares, ocupando 15\% do total da área da Bacia Hidrográfica do Arroio Pelotas.

Para o conhecimento das características naturais e das intervenções antrópicas, outros mapeamentos e cruzamentos de informações podem ser feitos a partir do mapa geomorfológico. Integrando informações dos tipos e uso de solos, é possível também avaliar os graus de fragilidade e potencialidade dos ambientes. Estudos geomorfológicos com uma escala de melhor detalhe devem ser feitos a fim de conhecer mais detalhes sobre o relevo destas áreas. 


\section{REFERÊNCIAS}

CHRISTOFOLETTI, A. Geomorfologia. São Paulo: Blucher, 1980.

FLORENZANO, T. G. Cartografia. In: (Org.). Geomorfologia: conceitos e tecnologias atuais. São Paulo: Oficina de Textos, 2008. p. 105-120.

FLORES, C. A. et al. Levantamento semidetalhado de solos: região da campanha: Folha Palomas, Estado do Rio Grande do Sul. Porto Alegre: UFRGS, 2007.

GUERRA, A. J. T.; MARÇAL, M. D. S. Geomorfologia ambiental. Rio de Janeiro: Bertrand Brasil, 2006.

HASENACK, H.; WEBER, E. (Org.). Base cartográfica vetorial contínua do Rio Grande do Sul: escala 1:50.000. Porto Alegre: Centro de Ecologia, UFRGS, 2010.

IBGE. Folha SH.22 Porto Alegre. Rio de Janeiro, 1986. (Levantamento de Recursos Naturais, v.33).

MARTH, J. D.; KOESTER, E.; ARNDT, A. L. Mapa geológico-geomorfológico do município de Pelotas. In: CONGRESSO DE INICIAÇÃO CIENTÍFICA, 17., ENCONTRO DE PÓSGRADUAÇÃO-ENPÓS, 10., Pelotas, RS. Anais... Pelotas, UFPEL, 2008. Disponível em: <http://www2.ufpel.edu.br/cic/2008/cd/pages/pdf/CE/CE_01239.pdf>. Acesso em: 10 jan. 2016.

MEGIATO, É. I. Análise da fragilidade ambiental da bacia hidrográfica do Arroio Pelotas, RS. 2011. Dissertação de Mestrado em Geografia - Departamento de Geociências, Universidade Federal do Rio Grande do Sul, Porto Alegre.

ROSS, J. L. S. Análise empírica da fragilidade dos ambientes naturais e antropizados. Revista do Departamento de Geografia, São Paulo, n. 8, 1994.

ROSS, J. L. S. Geomorfologia aplicada aos EIA-RIMAs. In: GUERRA, A. J. T.; CUNHA, S. B. (Org.). Geomorfologia e meio ambiente. Rio de Janeiro: Bertrand Brasil, 2000. p. 291 395.

ROSS, J. L. S. O registro cartográfico dos fatos geomorfológicos e a questão da taxonomia do relevo. Revista do Departamento de Geografia, São Paulo, n. 6, p. 17-29, 1992.

SUERTEGARAY, D. M. A.; FUJIMOTO, N. V. M. Morfogênese do relevo do Estado do Rio Grande do Sul. In: VERDUM, R.; BASSO, L. A.; SUERTEGARAY, D. M. A. (Org.). Rio Grande do Sul: paisagens e territórios em transformação. Porto Alegre: UFRGS, 2004. p. $11-26$.

VALERIANO, M. M. Dados Topográficos. In: FLORENZANO, T. G. (Org). Geomorfologia: conceitos e tecnologias atuais. São Paulo: Oficina de Textos, 2008. p. 72-93.

Recebido: abril de 2018. Aceito: setembro de 2018. 